\title{
Newer Effective Treatment for Adult Acute Asthmatics with a Multi-Dose Regimen of Ipratropium Bromide Plus Salbutamol Using Metered Dose Inhalers with a Spacer Device in Emergency Department
}

\author{
MM RASHID $^{\mathrm{a}}$, M M KHAIR $^{\mathrm{b}}$, MA HOSSAIN $^{\mathrm{c}}$, MR HASSAN $^{\mathrm{d}}$
}

\section{Summary:}

Aim of the study: To test the effectiveness of combined ipratropium bromide and salbutamol for treatment of adult patients with severe acute asthma

Type of study: This single-blind randomized controlled study was conducted in Emergency Department of National Institute Diseases of Chest and Hospital, Dhaka from July'05 to Dec'06.

Materials and Methods: Total 100 Adult patients (>18 yrs) of acute asthma with FEV1 30\%-50\% of predictive value were included in this study and two groups are done in randomized manner from random table. 51 patients (Study group) received a multi-dose regime of salbutmol and ipratropium bromide delivered by a metered dose inhaler (MDI) through a spacer device and 49 patients (control group) received similar doses of salbutmol by a metered dose inhaler (MDI) through an identical spacer device. Forced Expiratory Volume in $1^{\text {st }}$ second (FEV1), Peak Expiratory Flow (PEF), Saturation of oxygen (SO2), Respiratory rate (RR), Heart Rate (HT) that were recorded in a preformed questionnaire before starting treatment and at 30 minutes interval for $1 \frac{1}{2}$ hrs. All data were analyzed

Introduction:

Bronchial asthma is a common world-wide problem. According to WHO estimates, 235 million people suffer from asthma with an average of $7-10 \%$ worldwide ${ }^{1}$. As of 1998, there was a great disparity in the prevalence of

a. Dr. Md.Mamunur Rashid, MBBS, FCPS (Medicine), MD (Chest). National Institute of Diseases of Chest and Hospital (NIDCH), Dhaka

b. Dr. Mohammad Murtaza khair, Junior Consultant, NIDCH, Mohakhali, Dhaka

c. Prof. Md. Ali Hossain, Professor of Respiratory Medicine, NIDCH, Dhaka

d. Prof. Md. Rashidul Hassan, Director cum Professor, NIDCH, Dhaka

Address of Correspondence: Dr. Md.Mamunur Rashid, MBBS, FCPS (Medicine), MD (Chest). National Institute of Diseases of Chest and Hospital (NIDCH), Dhaka Cell: 01711903377. E-Mail: dr.mamun98@yahoo.com

Received: 25 January, 2012

Accepted: 23 September, 2012 with a "SPSS PC plus" software package and unpaired $t$ test was done during analysis

Results: Age of study group was $31.9 \pm 11.3$ (mean \pm SD) and control group was $32.5 \pm 13.7$ (mean $\pm S D$ ). The difference was not statistically significant $(p=0.82)$. Mean pre-treatment $\mathrm{FEV}, \mathrm{PEFR}, \mathrm{SO}_{2}$ in study group vs control group was $39.8 \%( \pm 4.8)$ vs $38.6( \pm 4.5), 137.2 \mathrm{~L} / \mathrm{min}$. ( \pm 32.8) vs $127.4 \mathrm{~L} / \mathrm{min}( \pm 32.0)$ and $94.5 \%$. ( \pm 2.8$)$ vs $93.4 \%$ ( \pm 2.3). The differences of pre-treatment values was not statistically significant $(P=0.5)$. After intervention, mean FEV1 values were $60 \%(S D, \pm 8.7), 71.4 \%,(S D, \pm 7.1)$, $80.5 \%,(S D \pm 7.3)$ in study group and $49.1 \% \pm 6.4,57.3 \%$ \pm 6.6 and $62.4 \% \pm 10.6$ (Mean $\pm S D)$ in control group at 30 mins, at 60 mins and at 90 mins respectively. The differences in FEV1 improvement is significant $(P<005)$ at all the three stages. Similarly, significant improvement of PEFR, SO2, Respiratory rate, Heart rate was also seen at all three stages after intervention.

Conclusion: The addition of ipratropium bromide to salbutamol demonstrated significant improvement over salbutamol alone in the treatment of adult acute asthmatics.

(J Bangladesh Coll Phys Surg 2012; 30: 195-200)

asthma across the world, with a trend toward more developed and westernized countries having higher rates of asthma ${ }^{2}$. The Centers for Disease Control and Prevention estimate that there were 1.75 million emergency department visits (1.11 million for adults and 0.64 million for children aged $0-17) ; 456,000$ asthma hospitalizations and 3,447 deaths due to asthma in 2007 in USA ${ }^{3}$. In 1994, approximately \$348 million was spent to provide care to acutely ill asthmatics in emergency departments ${ }^{3}$. Because of this common and expensive aspect of asthma care, better treatment strategies are needed to improve outcomes and to reduce the morbidity and expense associated with status asthmaticus.

Beta $_{2-}$ agonists have been shown to be effective and are recommended as first-line treatment of acute episodes of asthma ${ }^{4}$. The role of anticholinergic bronchodilators, including ipratropium, however, in the management of 
acute asthma is less clear ${ }^{5}$. The majority of autonomic nerves in human airways are branches of the vagus nerve, the efferent pre-ganglionic fibers of which enter the lung at the hilum and the efferent innervation is derived from the postganglionic fibers that end in the epithelium, submucosal glands and smooth muscle of the airways as well as in the vascular structures. Ipratropium bromide blocks muscarinic acetylcholine receptors and thereby decreasing contractility of smooth muscle in the lung, inhibiting bronchoconstriction and mucus secretion. Thus ipratropium bromide would antagonize this action of acetylecholine to cause brochodialation and reduction of bronchial secretion ${ }^{6}$.

A series of systematic reviews (Rodrigo GJ et al) have been conducted to clarify this point ${ }^{3}$. First, a review of 10 randomized controlled trials of children and adolescents receiving $\beta_{2}$-agonists for acute asthma with and without the addition of inhaled anticholinergics showed significant group differences in lung function supporting the combination treatment; additionally, multiple-dose anticholinergic protocols, mainly in children and adolescents with severe exacerbations, reduced the risk of hospital admission by $30 \%$. In a second meta-analysis (adult patients) of 10 randomized, double-blind, placebo-controlled trials, ipratropium bromide (IB) were associated with a significant increase in pulmonary function and a $27 \%$ reduction in hospital admissions. Finally, a third systematic review which included 10 randomized, double-blind, controlled trials with 1,483 adults with acute asthma showed a $10 \%$ increase in pulmonary function and a $38 \%$ reduction in hospital admission rate $^{3}$. Almost all these beneficial effects were observed with the utilization of single-dose protocols consisting of small doses of IB. Because there is substantial evidence that patients with acute asthma respond to increasing doses of bronchodilators, that thought can be applied to Ipratropium Bromide therapy.

Here I want to investigate the effectiveness of a multidose regime of salbutamol and ipratropium bromide inhalation in adult patients with acute asthma (FEV1 $30 \%-50 \%$ ) in comparison with salbutamol alone using a spacer device. This multi-dose protocol will be cheap, easy to administer by the patient and effectively control symptom and pulmonary function in acute asthmatics.

\section{Methodology:}

Type of Study: This Single-blind, randomized, controlled study done at Emergency Department of
National Institute Diseases of Chest and Hospital, Mohakhali, Dhaka from July'05 to Dec'06.

\section{Selection of Patients:}

Inclusion Criteria:

1. Established cases of bronchial asthma.

2. $\mathrm{FEV}_{1} 30 \%-50 \%$ of predictive value.

3. Adult patient ( $>18$ yrs).

4. Both sexes.

\section{Exclusion criteria:}

1. Long history of smoking, COPD. Chronic cough, old $\mathrm{TB}$, fever $\left(>38^{\circ} \mathrm{C}\right)$.

2. Co-morbidity - Malignancy, CCF, CRF, CLD etc.

3. Those already received aminphylline drip, injectable steroid

4. Pregnancy, bladder dysfunction, prostatitis.

5. Unable to blow.

\section{Materials and Methods:}

A series of hundred patients fulfilling those criteria were enrolled in this study and two groups were done at random from random table. One group received metered dose inhalers labelled $\mathrm{A}$ and another group received metered dose inhalers labelled B through a spacer device at a dose of four puffs / 10 minutes interval for $1 \frac{1}{2} \mathrm{hrs}$. Inhalers labelled A contains salbutamol and ipratropium bromide (100 $\mu \mathrm{gm}$ salbutamol sulphate and $20 \mu \mathrm{gm}$ ipratropium bromide per puff) and label B inhalers contains salbutamol (100 $\mu \mathrm{gm} / \mathrm{puff})$. Other modalities of treatment in emergency department like nebulized or injectable bronchodialators, corticosteroid (oral or injectable) were avoided in both groups with caution. Administration of high flow 02 was allowed in both groups if $\mathrm{SO}_{2}$ reduces to $92 \%$. Forced Expiratory Volume in $1^{\text {st }}$ second (FEV1), Peak Expiratory Flow (PEF), Saturation of oxygen $\left(\mathrm{SO}_{2}\right)$, Respiratory rate (RR), Heart Rate (HT) were the variables that were recorded in a preformed questionnaire form immediately before starting treatment and at 30,60 and 90 minutes. PEF were measured with mini-wright peak flow meter and $\mathrm{FEV}_{1}$ were recorded with a vitalograph compact spirometer. At the end of therapy each patient were asked for nausea, palpitation, tremor, anxiety, headache, dry mouth and if present, were noted.

At the end of protocol, every patient were assessed clinically \& PFT and those with improved dyspoea and 
of $\mathrm{PEF}$ or $\mathrm{FEV}_{1}>60 \%$ of predictive value were discharged with oral prednisolone and bronchodialators. Those didn't fulfilling the criteria for discharge were admitted and treated accordingly.

\section{Statistical Analysis:}

All data were analyzed with a "SPSS PC plus" software package (SPSS Inc., Chicago, IL) and unpaired t test was done during analysis.

\section{Ethical Issue:}

This work has been done as a pre-requisite of MD (Chest Diseases) thesis examination. The ethical clearance was taken from the thesis committee of National Institute of diseases of chest and Hospital (NIDCH) which is an authentic body to give ethical clearance, approved by Bangladesh Medical Research Council (BMRC).

\section{Results:}

This single-blind, randomized, controlled study included total 100 patients with acute asthma who have fulfilled the inclusion and exclusion criteria and was divided into two groups at random. Ipratropium bromide (Label A) group had total 51 patients and Control group (Label B) had 49 patients.

Age of IB group was $31.9 \pm 11.3($ mean \pm SD) and control group was $32.5 \pm 13.7$ (mean $\pm \mathrm{SD}$ ). The difference was not statistically significant $(p=0.82)$. Among IB group patients, highest percentage of patients $(25.5 \%)$ were in the age group 21-30 years followed by $19.6 \%$ in the age group $31-40$ years, $17.4 \%$ in the age group 41-50 years and below 20 age group. Similar age pattern was found in the control group patients with highest percentage ( $28.6 \%$ ) were in the age group 3140 years followed by $26.5 \%$ in the age group 21-30 years and also below 20 age group and lowest in the age group 41-50 years (10.2\%).

Among IB group patients, highest percentage were male $(62.7 \%)$ and female were $37.3 \%$. In control group patients, highest percentage were male $(61.1 \%)$ and female were $38.8 \%$. No statistically significant sex difference was found between the two groups of patients $(\mathrm{p}>0.05)$.

\section{$\mathrm{FEV}_{1}$ :}

Mean pre-treatment $\mathrm{FEV}_{1}$ was in study group $39.8 \%$ $(\mathrm{SD}, \pm 4.8)$ and in control group was $38.6(\mathrm{SD}, \pm 4.5)$. The difference of pre-treatment $\mathrm{FEV}_{1}$ values was not statistically significant $(\mathrm{P}=0.19)$. After intervention, mean FEV1 values were $60 \%$ (SD, \pm 8.7$), 71.4 \%$, (SD, $\pm 7.1), 80.5 \%,(\mathrm{SD} \pm 7.3)$ in study group and $49.1 \% \pm$ $6.4,57.3 \% \pm 6.6$ and $62.4 \% \pm 10.6($ Mean \pm SD) at 30 mins, at $60 \mathrm{mins}$ and at $90 \mathrm{mins}$ respectively. The difference in FEV1 improvement is significant $(\mathrm{P}<.005)$ at all the three stage.

\section{PEFR:}

Mean pre-treatment PEFR was in study group $137.2 \mathrm{~L} /$ min. (SD, \pm 32.8 ) and in control group was $127.4 \mathrm{~L} /$ min. (SD, \pm 32.0$)$. The difference of pre-treatment PEFR values was not statistically significant $(\mathrm{P}=0.19)$. After intervention, mean PEFR were 186.4 L/min. ( \pm 40.1$)$, 212.7 L/min., ( \pm 41.7$), 243 \mathrm{~L} / \mathrm{min} .( \pm 53.3)$ in study group and $146.7 \mathrm{~L} / \mathrm{min} .( \pm 36.3), 161.1 \mathrm{~L} / \mathrm{min} .( \pm 33.8)$ and173.1 L/min. (SD \pm 37.8$)$ at $30 \mathrm{mins}$, at $60 \mathrm{mins}$ and at 90 mins respectively. The difference in PEFR improvement is significant $(\mathrm{P}<.005)$ at all the three stage.

$\mathrm{SO}_{2}:$

Mean pre-treatment $\mathrm{SO}_{2}$ was in study group $94.5 \%$. (SD, \pm 2.8 ) and in control group was $93.4 \%(\mathrm{SD}, \pm 2.3)$. The difference of pre-treatment $\mathrm{SO}_{2}$ values was not statistically significant ( $\mathrm{P}=0.03)$. After intervention, mean $\mathrm{SO}_{2}$ were $97.8 \%(\mathrm{SD}, \pm 1.0), 98.6 \%(\mathrm{SD}, \pm 0.5)$, $98.8 \%(\mathrm{SD}, \pm 0.4)$ in study group and $95.9 \%(\mathrm{SD}, \pm$ 1.8), $97.1(\mathrm{SD}, \pm 1.5)$ and $97.9 \%(\mathrm{SD}, \pm 1.0)$ at $30 \mathrm{mins}$, at 60 mins and at 90 mins respectively. The difference in $\mathrm{SO}_{2}$ improvement is significant $(\mathrm{P}<.005)$ at all the three stage.

\section{Respiratory rate:}

Mean pre-treatment respiratory rate was in study group $33.7 / \mathrm{min}$. (SD, \pm 4.6 ) and in control group was 34.3/ min. (SD, \pm 3.7 ). The difference of pre-treatment respiratory rate values was not statistically significant $(\mathrm{P}=0.46)$. After intervention, mean respiratory rate were $26.7 / \mathrm{min}$. ( \pm 4.5$), 21.4 / \mathrm{min}$. (SD, \pm 4.2$), 18.8 / \mathrm{min}$ (SD, \pm 2.4 ) in study group and $29.4 / \mathrm{min}$. (SD, \pm 3.0 ), 26 / $\mathrm{min} .( \pm 2.8)$ and $23.4 / \mathrm{min}$. $(\mathrm{SD} \pm 1.0)$ at $30 \mathrm{mins}$, at 60 mins and at 90 mins respectively. The difference in respiratory rate improvement is significant $(\mathrm{P}<.005)$ at all the three stage.

\section{Heart rate:}

Mean pre-treatment heart rate was in study group 125.8 /min. (SD, \pm 12.2 ) and in control group was $127.5 / \mathrm{min}$. 
$(\mathrm{SD}, \pm 13.2)$. The difference of pre-treatment heart rate values was not statistically significant $(\mathrm{P}=0.5)$. After intervention, mean heart rate were $110.9 / \mathrm{min}$. (SD, \pm 10.2), $100.4 / \mathrm{min}$. (SD, \pm 9.9 ), $93.7 / \mathrm{min}(\mathrm{SD}, \pm 10.0)$ in study group and $117.1 / \mathrm{min} .(\mathrm{SD}, \pm 11.7), 109.5$ / min. $(\mathrm{SD}, \pm 10.7)$ and $102.3 / \mathrm{min} .(\mathrm{SD}, \pm 9.1)$ at 30 mins, at 60 mins and at 90 mins respectively. The difference in heart rate improvement is significant $(\mathrm{P}<.005)$ at 60 and 90 mins.
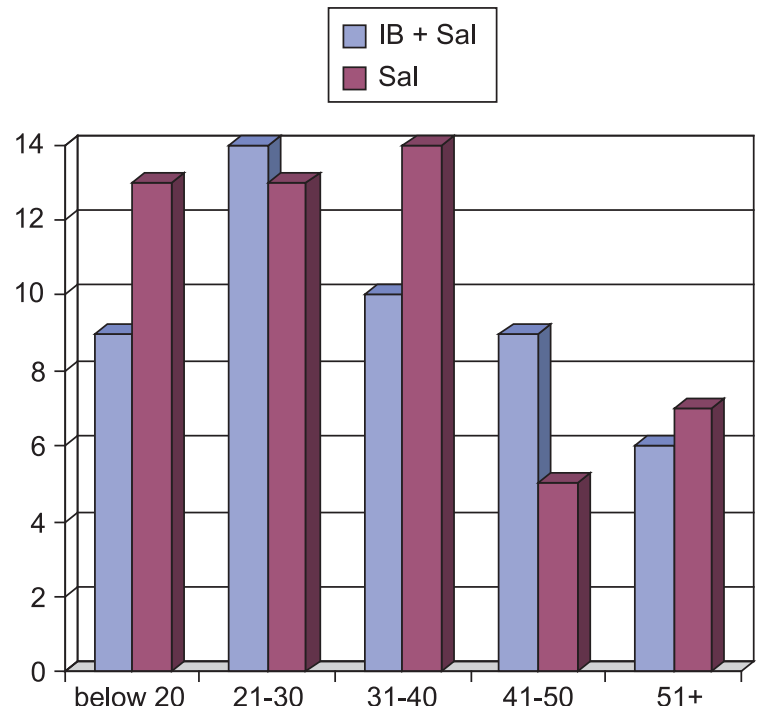

Fig.-1: Graphic presentation of age distribution in two groups in studied patients.
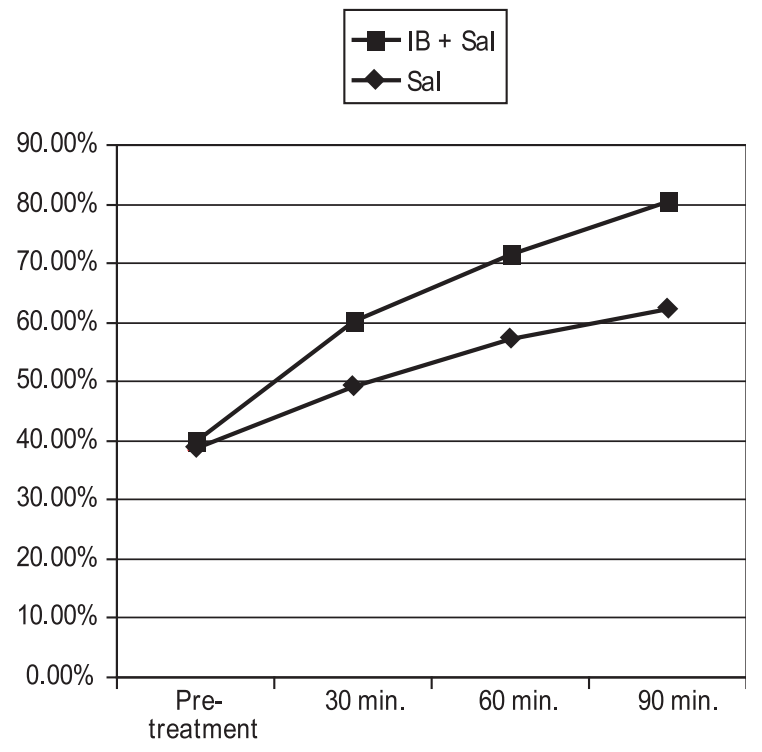

Fig.-2: Changes of FEV, before and intervention in two groups of patients in studied population.

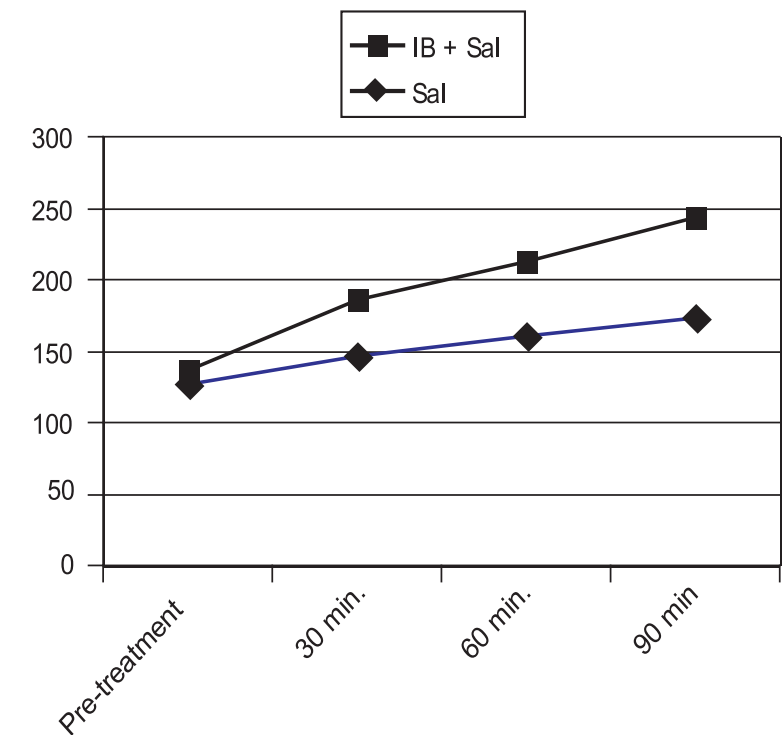

Fig.-3: Changes of PEFR before and intervention in two groups of patients in studied population

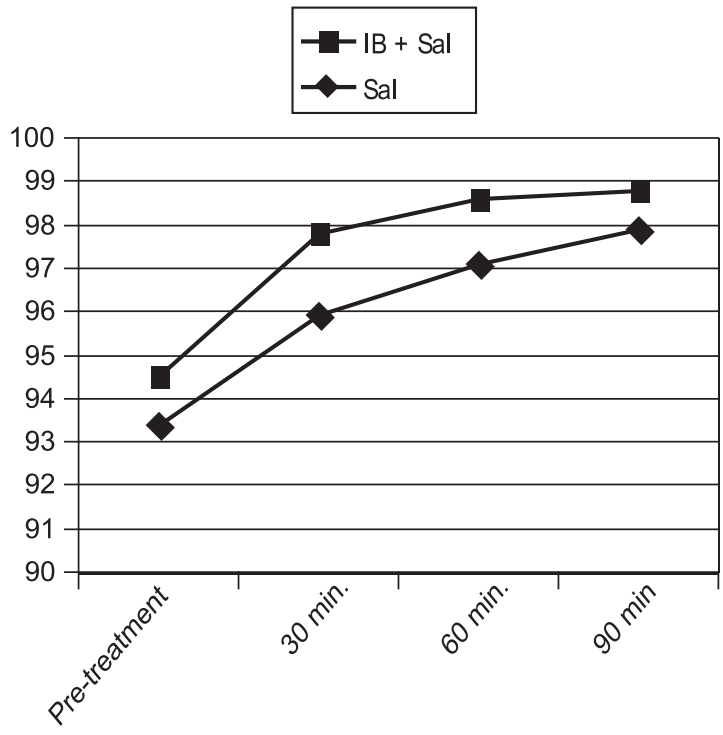

Fig.-4: Changes of $\mathrm{SO}_{2}$ before and intervention in two groups of patients in studied population

\section{Discussion:}

Mean age of study group was 31.9 years ( $\mathrm{SD}, \pm 11.3$ ) and control group was 32.5 yrs $(\mathrm{SD}, \pm 13.7)$ The difference was not statistically significant $(\mathrm{p}=0.82)$. Highest percentage of patients $(50 \%)$ was between 21 40 years and lowest (15\%) in 51 and above age group. So, this study revealed that the productive age groups patients are mainly affected by acute asthma. 
This randomized, single-blind, controlled study demonstrated a significant advantage of higher multiple intermittent doses of ipratropium bromide and salbutamol over same doses of salbutamol alone delivered through identical spacer device in the emergency treatment of adult acute severe asthma. The $\mathrm{FEV}_{1}$, PEFR, SO2, Heart rate (HR) and Respiratory Rate (RR) were the variables used in this study to compare the improvements. These are the qualitative and unique variables used to measure air-flow limitations in respiratory medicine. Both these parameters showed significant improvement as quicker as at 30 minutes. And it lasts at 1 hour and at $11 / 2 \mathrm{hrs}$. This finding proved that the response was very quick and persistent with the addition of ipratropium bromide to salbutamol.

A randomized, single-blind, placebo-controlled trial was performed by Nakano et al to compare the outcomes of adults with acute severe asthma (PEF, $<50 \%$ of predicted) who had been treated with 4 puffs $(400 \mu \mathrm{g})$ salbutamol plus 4 puffs of oxitropium bromide $(40 \mu \mathrm{g})$ every $20 \mathrm{~min}$ for three doses to the administration of salbutamol $(400 \mu \mathrm{g})$ alone by means of an MDI with a spacer device in 74 adult patients presenting to the ED for treatment ${ }^{7}$. The increase in PEF over the course of treatment was significantly greater in the oxitropium bromide-plus-salbutamol group. The mean absolute difference in PEF at $120 \mathrm{~min}$ for patients receiving combination therapy compared with those receiving salbutamol alone was $37.8 \mathrm{~L} / \mathrm{min}$. They found that patients with more severe asthma (ie, baseline PEF, < $200 \mathrm{~L} / \mathrm{min}$ ) benefited from the addition of oxitropium bromide to salbutamol. This study was similar to ours where ipratropium bromide was used instead of oxitropium and showed the improvement of PEFR by $70 \mathrm{~L} /$ minutes after 90 mins.

Rodrigo GJ et al designed a large, double-blind, randomized controlled trial to test the hypothesis that adult patients with acute severe asthma (ie, $\mathrm{FEV}_{1},<50 \%$ of predicted) who are given combination high-dose therapy with ipratropium bromide and $\beta_{2}$-agonist agents will have greater improvement in pulmonary function and fewer hospital admissions than those given $\beta_{2}$ agonist agents alone ${ }^{8}$. One hundred eighty patients who had presented to an ED were assigned in a randomized, double-blind fashion to receive salbutamol and placebo or salbutamol and ipratropium bromide (both drugs were administered through an MDI and spacer at 10-min intervals for $3 \mathrm{~h}, 24$ puffs, or 2,880 $\mu \mathrm{g}$ albuterol and $504 \mu \mathrm{g}$ ipratropium bromide each hour). At the end of treatment, subjects who had received ipratropium bromide had an overall $48.1 \%$ greater improvement in $\mathrm{FEV}_{1}$ than those in the control group. At $90 \mathrm{~min}$, the response in the ipratropium bromide group was significantly higher compared to that in the control group. At the end of the protocol (ie, after $3 \mathrm{~h}$ ), 39\% of patients in the control group and $20 \%$ of patients in the ipratropium bromide group were admitted to the hospital. The use of high doses of ipratropium bromide reduced the risk of hospital admission by $49 \%$. This is similar to our study that showed significant improvement in terms of symptoms, pulmonary function.

Continuous nebulization is thought to be more beneficial than intermittent therapy; however, a recently published meta-analysis of randomized controlled trials by Rodrigo GJ et al on adult acute asthmatics found no significant differences between the two methods in terms of pulmonary function improvement or hospital admission ${ }^{9}$. These findings argue against the routine use of continuous nebulization in the ED treatment of patients with acute asthma. On the other hand, administration of beta-agonist bronchodilators by metered-dose inhaler (MDI) is as effective as administration by hand-held nebulizer (NEB) ${ }^{10}$. So, a multi-dose regime administered by MDI with spacer device which was used in our study is quite rational and effective. Administration of beta-agonist bronchodilators by metered-dose inhaler (MDI) is as effective as administration by hand-held nebulizer (NEB).

In our study, the cost effectiveness can't be evaluated, but a good number of studies conducted outside our country shown its favor towards combination therapy. A cost-effectiveness analysis by Lord et al on inhaled anti-cholinergic agents for the treatment of acute childhood and adolescent asthma estimated a net saving of $<£ 80$ per severe case that was treated ${ }^{11}$. In addition to efficacy, the methods of drug administration will influence the decision to use anti-cholinergic agents for acute asthma. The costs for nebulized therapy are necessarily higher than for MDI therapy because the administration of the nebulization therapy must be performed by trained health-care personnel, and the tubing and masks used for nebulization must be discarded after patient use. It has been shown that the 
routine substitution of an MDI with a spacer device saves hospital resources ${ }^{10}$. There is significant evidence that anti-cholinergic and $\beta_{2}$-agonist medications can be delivered effectively to patients with acute asthma by means of an MDI with a spacer in less time, with lower costs, and with minimal toxicity ${ }^{10}$.

All these evidences made in our study and studies all over the world demonstrated that addition of ipratropium bromide to salbutamol in multiple intermittent doses is very effective in bronchodialation and reduction of hospital admission of acute asthmatics in both adult and children, thereby reduce the overall cost of treatment and reduce loss of working period of the productive age group patients which is very important for a developing country like Bangladesh.

\section{References:}

1. World Health Organization. Asthma. Accessed on $18^{\text {th }}$ August 2011. At: http://www.who.int/respiratory/asthma/en/

2. Asthma-Wikipedia. Accessed on $18^{\text {th }}$ August, 2011 at: http:// en.wikipedia.org/wiki/Asthma

3. Akinbami LJ and Moorman JE. Asthma Prevalence, Health Care Use and Mortality: United States, 2005-2009. National Health Statistics Report. Number 32, January 12, 2011. Available at: http://www.cdc.gov/asthma/asthmadata.htm
4. British Thoracic Society and others. Guidelines on the management of asthma: management of acute asthma. Thorax 2003; 58: i32-i50

5. Rodrigo GJ and Rodrigo C. First-Line Therapy for Adult Patients with Acute Asthma Receiving a Multiple-Dose Protocol of Ipratropium Bromide Plus Albuterol in the Emergency Department. Am. J. Respir. Crit. Care Med., 2000; 161; 1862-68

6. Ipratropium bromide- Wikipedia. Accessed on $19^{\text {th }}$ August 2001 at: http://en.wikipedia.org/wiki/Ipratropium_bromide

7. Nakano Y, Enomoto N, Kawamoto A et al. Efficacy of adding multiple doses of oxitropium bromide to salbutamol delivered by means of a metered-dose inhaler with spacer device in adults with acute severe asthma. J Allergy Clin Immunol 2000;106:472-78.

8. Rodrigo GJ and Rodrigo C. The Role of Anti-cholinergics in Acute Asthma Treatment: An Evidence-Based Evaluation. Chest 2002; 121:1977-87.

9. Rodrigo GJ and Rodrigo C. Continuous vs intermittent betaagonists in the treatment of acute adult asthma: a systematic review with meta-analysis. Chest. 2002; 122:160-65.

10. Bowton DL, Goldsmith WM and Haponik EF. Substitution of metered-dose inhalers for hand-held nebulizers. Success and cost savings in a large, acute-care hospital. Chest 1992; 101: 305-8.

11. Lord J, Ducharme FM, Stamp RJ et al. Cost effectiveness analysis of inhaled anticholinergics for acute childhood and adolescent asthma. BMJ 1999;319: 1470-71. 